\title{
Expression of interleukin-24 and its receptor in human pancreatic myofibroblasts
}

\author{
HIROTSUGU IMAEDA ${ }^{1}$, ATSUSHI NISHIDA ${ }^{1}$, OSAMU INATOMI ${ }^{1}$, \\ YOSHIHIDE FUJIYAMA $^{1}$ and AKIRA ANDOH ${ }^{2}$ \\ ${ }^{1}$ Department of Medicine and ${ }^{2}$ Division of Mucosal Immunology, Graduate School of Medicine, \\ Shiga University of Medical Science, Seta Tsukinowa, Otsu, Japan
}

Received July 12, 2011; Accepted August 30, 2011

DOI: $10.3892 /$ ijmm.2011.793

\begin{abstract}
Interleukin (IL)-24 is a member of the IL-10 family of cytokines. In this study, we investigated IL-24 expression in chronic pancreatitis tissue and characterized the molecular mechanisms responsible for IL-24 expression in human pancreatic myofibroblasts. IL-24 expression in the tissues was evaluated by immunohistochemical methods. IL-24 mRNA and protein expression in the pancreatic myofibroblasts was determined by real-time-PCR and ELISA, respectively. IL-24 was expressed by $\alpha$-smooth muscle actin-positive myofibroblasts in the chronic pancreatitis tissues. In isolated human pancreatic myofibroblasts, IL-1 $\beta$ significantly enhanced IL-24 mRNA and protein expression. The p38 MAPK inhibitor SB203580 and the PI3K inhibitor LY294002 significantly reduced the IL- $\beta$-induced IL-24 mRNA expression. An adenovirus containing a dominant-negative mutant of c-Jun significantly inhibited the effects of IL-1 $\beta$ on IL-24 mRNA expression, indicating that the IL-1 $\beta$-induced IL- 24 mRNA expression was mediated by the activation of transcription factor AP-1. Pancreatic myofibroblasts expressed IL-22R1, IL-20R1 and IL-20R2, and recombinant IL-24 induced the phosphorylation of p42/44, p38, JNK and STAT1/3. IL-24 is expressed in chronic pancreatitis tissue, and may play a role in the pathophysiology of chronic pancreatitis via autocrine pathways.
\end{abstract}

\section{Introduction}

Fibrosis of the pancreas is one of the characteristic histopathologic findings in cases of chronic pancreatitis and the desmoplastic reaction associated with pancreatic cancer. Previous studies have demonstrated that pancreatic myofi-

Correspondence to: Dr Akira Andoh, Division of Mucosal Immunology, Graduate School of Medicine, Shiga University of Medical Science, Seta Tsukinowa, Otsu 520-2192, Japan

E-mail: andoh@belle.shiga-med.ac.jp

Key words: MAP-kinase, AP-1, chronic pancreatitis, interleukin-1 $\beta$ broblasts play a pivotal role in the progression of pancreatic fibrosis (1-6). Pancreatic myofibroblasts actively proliferate, migrate and produce large amounts of extracellular matrix (ECM) components such as type I collagen and fibronectin. In addition, these cells possess proinflammatory functions characterized by the expression of cytokines, chemokines and cell adhesion molecules (1-6).

Interleukin (IL)-24, a member of the IL-10 family of cytokines (together with IL-10, -19, -20, -22, -26, -28 and -29), was originally termed melanoma differentiation-associated protein 7 (MDA-7) (7), and was renamed IL-24 (8). The human $I L-24$ gene is located on chromosome 1 , within a 195-kb cytokine cluster containing the IL-10, IL-19, IL-20 and IL-24 genes (9). IL-24 shares a 20-30\% amino acid homology with IL-10, IL-20 and IL-22, and interacts with two different heterodimeric receptor complexes, IL-20R1/IL-20R2 and IL-22R1/IL-20R2 (10-12). Binding to both receptors leads to the activation of signal transducer and activator of transcription 3 (STAT3) (10-13). Immune cells do not express IL-24 receptors (14), suggesting that IL-24 cannot stimulate the acquired immune response (15). In contrast, the restricted expression of the IL-24R components IL-20R1 and IL-22R1 to non-immune tissues suggests that the innate immune response is the selective target of IL-24 $(11,14)$.

IL-24 expression has been identified in certain cell types $(14,16)$, such as cultured melanocytes $(7)$, dermal keratinocytes (15), lipopolysaccharide (LPS)-stimulated monocytes (16) and Th2-polarized T cells (16). Furthermore, treatment with IFN- $\beta$ plus mezerein was found to induce a transient expression of IL-24 mRNA in some cancer cell lines (9). However, the precise molecular mechanisms of IL-24 induction still remain unclear.

In the present study, we investigated IL-24 expression in chronic pancreatitis tissues. Furthermore, to investigate the molecular mechanisms responsible for IL-24 expression in the pancreas, we analyzed IL-24 expression in human pancreatic myofibroblasts.

\section{Materials and methods}

Reagents. Recombinant human cytokines were purchased from R\&D Systems (Minneapolis, MN). Inhibitors for the p42/44 MAP-kinases (PD98059 and U0216), and an inhibitor for 
Table I. Oligonucleotides used in this study.

\begin{tabular}{lllc}
\hline Gene name & \multicolumn{1}{c}{ Primers } & Ref. \\
\hline IL-24 & Sense & 5'-GACTTTAGCCAGCAGACCCTT-3' & 8 \\
& Antisense & 5'-GGTTGCAGTTGTGACACGAT-3' & 14 \\
IL-22R1 & Sense & 5'-CTGTCCGAGATCACCTACTTAGG-3' \\
& Antisense & 5'-GCACATTTGGGTCAGATGTTCTGTC-3' \\
IL-20R1 & Sense & 5'-GCTCAGCCTTCTGAGAAGCAGTG-3' & 20 \\
& Antisense & 5'-CGCACAAATGTCAGTGGTTCTGAC-3' \\
IL-20R2 & Sense & 5'-GCTGGTGCTCACTCACTGAAGGT-3' & 20 \\
& Antisense & 5'-TCTGTCTGGCTGAAGGCGCTGTA-3' \\
\hline
\end{tabular}

IL-24

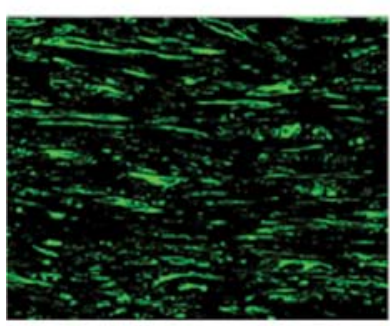

a-SMA

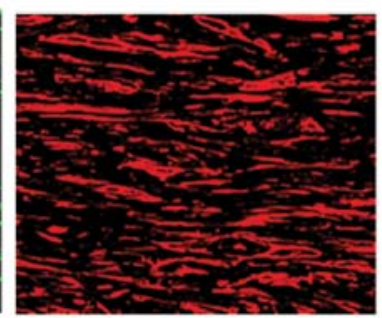

merged

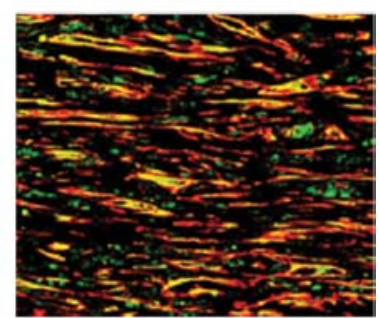

Figure 1. Representative immunohistochemical staining for IL-24 and $\alpha$-smooth muscle actin ( $\alpha$-SMA) in chronic pancreatitis tissues. IL-24 protein was clearly detected in the spindle-shaped cells (green fluorescence; left panel). Myofibroblasts were detected as $\alpha$-SMA-immunopositive cells (red fluorescence; middle panel). $\alpha$-SMA/IL-24 double-immunopositive cells were detected as yellow, and the $\alpha$-SMA-immunopositive cells coincided with some of the IL-24immunopositive cells (right panel). Magnification, x200.

p38 MAPK (SB203580) were purchased from Cell Signaling Technology (Beverly, MA). The procollagen type I C-peptide EIA kit was purchased from Takara Bio (Otsu, Japan).

Antibodies. Goat anti-human IL-24 antibodies (R\&D System), mouse anti- $\alpha$-SMA antibodies (Sigma Chemical Co., St. Louis, MO), goat anti-JAK1 antibodies, anti-MAP kinase, and anti-STAT1 and 3 antibodies (Cell Signaling Technology), goat anti-human c-Jun and c-Fos antibodies (Santa Cruz Biotechnology, Santa Cruz, CA, USA) were purchased from commercial suppliers.

Tissue samples and immunochemistry. Human pancreatic tissues were obtained from patients with clinically diagnosed chronic pancreatitis undergoing surgery for intractable back pain, or from patients with significant suspicion of pancreatic cancer. Normal pancreatic tissues were obtained from patients who underwent total gastropancreatectomies due to gastric cancer. The study design was approved by the Ethics Committee of the Shiga University of Medical Science. Informed consent was obtained from all patients prior to sample collection.

Paraffin-embedded tissues were cut into $3 \mu \mathrm{m}$ sections. Goat anti-human IL-24 antibodies and anti-human $\alpha$-SMA antibodies were then applied. Cy2-labeled anti-goat rabbit IgG (Chemicon, Temecula, CA) and Cy3-labeled anti-mouse donkey IgG (Millipore, Billerica, MA) were used as the secondary antibodies. The slides were analyzed for fluores- cence using a digital confocal laser scanning microscope (LSM510 ver. 3.0; Carl Zeiss Japan, Tokyo, Japan). Standard immunohistochemical analyses were performed according to the methods described in our previous report (17).

Human pancreatic myofibroblast cultures. Primary cultures of pancreatic myofibroblasts were isolated from normal pancreatic tissues obtained from patients who underwent total gastropancreatectomies due to gastric cancer, according to methods previously described (4). The cells were cultured in DMEM containing 10\% FBS. All culture media were supplemented with $50 \mathrm{U} / \mathrm{ml}$ penicillin and $50 \mu \mathrm{g} / \mathrm{ml}$ streptomycin. Over $98 \%$ of the cells were immunopositive for $\alpha$-SMA, a marker for myofibroblasts. The studies were performed on passages 2-6 of myofibroblasts isolated from 4 different resection specimens.

Quantification of human IL-24 and IL-24R. Antigenic IL-24 in all samples was quantified by sandwich enzyme-linked immunosorbent assay (ELISA) kits purchased from R\&D systems. The expression of mRNA in the samples was assessed by realtime PCR analysis. The oligonucleotide primers used in this study were described in our previous report (18). Real-time PCR was performed using a LightCycler 2.0 system (Roche Applied Science, Tokyo, Japan). The PCR was performed using a SYBR-Green PCR master mix (Applied Biosystems, Foster City, CA). The oligonucleotide primers used in this study are shown in Table I $(7,13,19)$. The data were normalized versus $\beta$-actin for human IL-24. The expression of IL-24R mRNA 
A

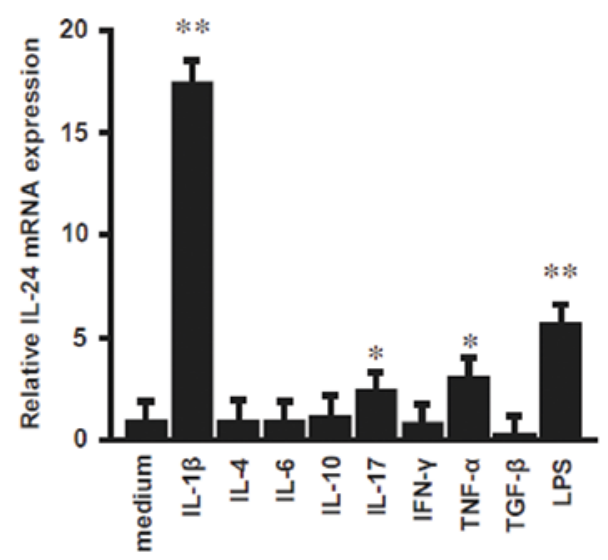

B

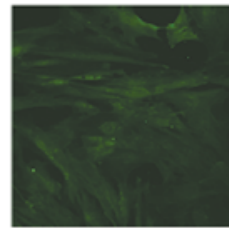

medium

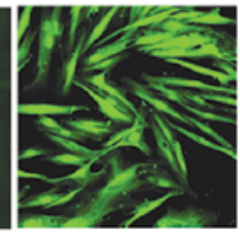

IL-1 $\beta$

$(100 \mathrm{ng} / \mathrm{mL})$

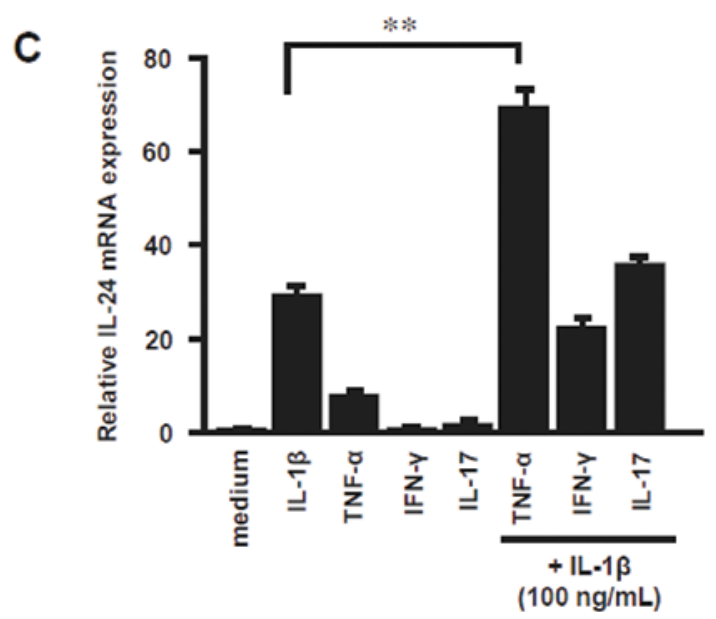

Figure 2. IL-24 mRNA expression in human pancreatic myofibroblasts. (A) The cells were stimulated with cytokines $(100 \mathrm{ng} / \mathrm{ml})$ or lipopolysaccharide (LPS; $1 \mu \mathrm{g} / \mathrm{ml}$ ) for $24 \mathrm{~h}$. IL-24 mRNA expression was then analyzed by real-time PCR. (B) Immunostaining for IL-24 in cultured pancreatic myofibroblasts. The cells were cultured on a chamber slide glass for $24 \mathrm{~h}$ in the presence or absence of IL-1 $\beta(10 \mathrm{ng} / \mathrm{ml})$ and immunostained with anti-human IL-24 antibodies. (C) Combined effects of cytokines on IL-24 mRNA expression. The cells were stimulated with IL-1 $\beta(100 \mathrm{ng} / \mathrm{ml})$, TNF- $\alpha(100 \mathrm{ng} / \mathrm{ml})$, IFN- $\gamma(100 \mathrm{ng} / \mathrm{ml})$, IL-17 $(100 \mathrm{ng} / \mathrm{ml})$ and combinations of these factors for $24 \mathrm{~h}$, and then the IL-24 mRNA expression was determined by real-time PCR. The figures from the real-time PCR were expressed as the IL-24 mRNA expression relative to the $\beta$-actin mRNA expression (mean \pm SD from 4 different experiments). ${ }^{* *} \mathrm{P}<0.01$ vs. medium only.

was assessed by reverse-transcription (RT)-PCR analyses according to methods described in our previous report (20).

Adenovirus-mediated gene transfers. We used a recombinant adenovirus expressing a dominant-negative mutant of c-Jun (Ad-DN-c-Jun), and a recombinant adenovirus containing bacterial $\beta$-galactosidase cDNA (Ad-LacZ). The dominantnegative mutant c-Jun (TAM67) lacks the transactivational domain of amino acids 3 to 122 of the wild type c-Jun (21), but retains the DNA-binding domain. The detailed procedures have been described in our previous report (22).

Statistical analysis. The statistical significance of the differences was determined by the Mann-Whitney U test (Statview version 4.5). Differences resulting in P-values <0.05 were considered to be statistically significant.

\section{Results}

IL-24 expression in chronic pancreatitis. To evaluate the expression of IL-24 mRNA in the pancreas, the tissues of chronic pancreatitis patients were double immunostained with anti-human IL-24 antibodies and anti- $\alpha$-smooth muscle actin ( $\alpha$-SMA; a marker for myofibroblasts) antibodies (Fig. 1). IL-24 protein was clearly detected in the spindle-shaped cells (green fluorescence; Fig. 1, left panel). Myofibroblasts were detected as $\alpha$-SMA-positive cells (red fluorescence; Fig. 1, middle panel). As shown in Fig. 1 (right panel) the $\alpha$-SMA/ IL-24-double immunopositive cells were detected as yellow, and the IL-24-immunopositive cells coincided with part of the $\alpha$-SMA-immunopositive cells. These observations indicated that $\alpha$-SMA-immunopositive myofibroblasts expressed IL-24 in the chronic pancreatitis tissues.

Regulation of IL-24 expression in pancreatic myofibroblasts. Based on the in vivo expression of IL-24 in chronic pancreatitis tissues, we examined IL-24 expression in isolated human pancreatic myofibroblasts. The cells were stimulated with various cytokines and LPS for $12 \mathrm{~h}$, and then the IL-24 mRNA expression was determined by real-time PCR (Fig. 2A). Very weak IL-24 mRNA expression was detected in the unstimulated pancreatic myofibroblasts, and IL- $1 \beta$ stimulation significantly enhanced this IL-24 mRNA expression. IL-17, TNF- $\alpha$ and LPS all weakly enhanced IL-24 mRNA expression, but these effects were much weaker than those induced by IL-1 $\beta$. IL-24 protein expression and its induction by IL-1 $\beta$ were both detected in cultured pancreatic myofibroblasts by immunofluorescent staining (Fig. 2B). The combination of IL-1 $\beta$ and TNF- $\alpha$ markedly enhanced IL-24 mRNA expression, and this was observed as an additive effect (Fig. 2C).

Pancreatic myofibroblasts were stimulated with increasing concentrations of IL- $1 \beta$ for $24 \mathrm{~h}$, and the IL-24 mRNA expression was determined by real-time PCR. IL-1 $\beta$ dosedependently induced IL-24 mRNA expression (Fig. 3A). Looking at the kinetics of IL-24 mRNA expression in response to IL-1 $\beta$, the cells were stimulated with IL-1 $\beta(100 \mathrm{ng} / \mathrm{ml})$, and IL-24 mRNA expression was sequentially determined. IL-1 $\beta$ time-dependently induced IL-24 mRNA expression (Fig. 3B).

Similar effects of IL-1 $\beta$ were investigated at the protein level. Pancreatic myofibroblasts were stimulated with various concentrations of IL-1 $\beta$ for $48 \mathrm{~h}$, and then the IL-24 secretion was determined by ELISA. IL- $1 \beta$ dose-dependently induced IL-24 secretion (Fig. 3C). Furthermore, the cells were incubated with IL-1 $\beta(100 \mathrm{ng} / \mathrm{ml})$ for $48 \mathrm{~h}$, and then the IL-24 protein secretion was analyzed sequentially by ELISA. This IL-24 secretion was observed in a time-dependent manner (Fig. 3D). 
A

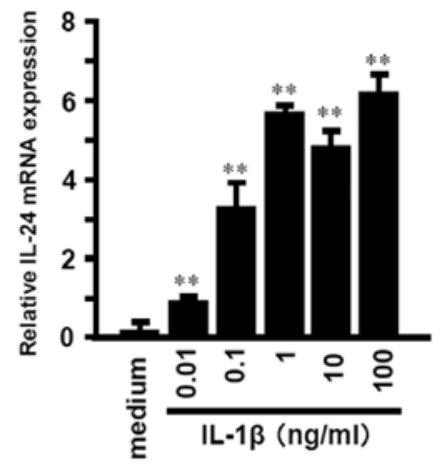

C

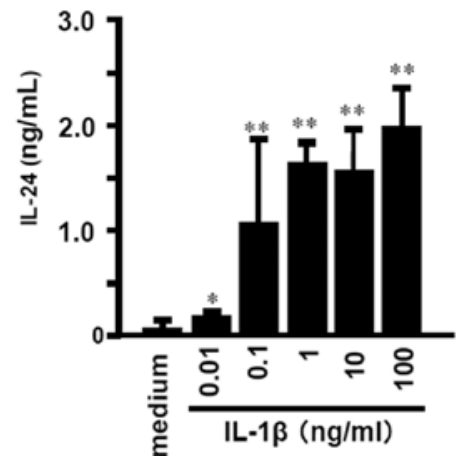

B

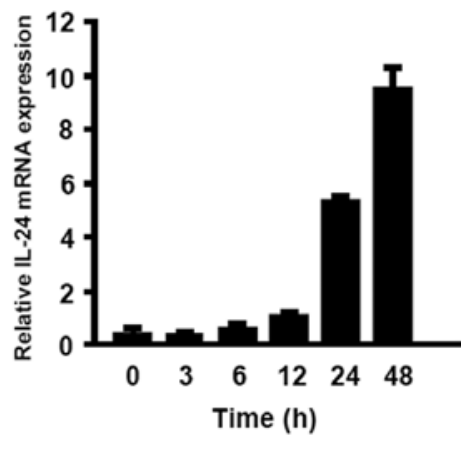

D

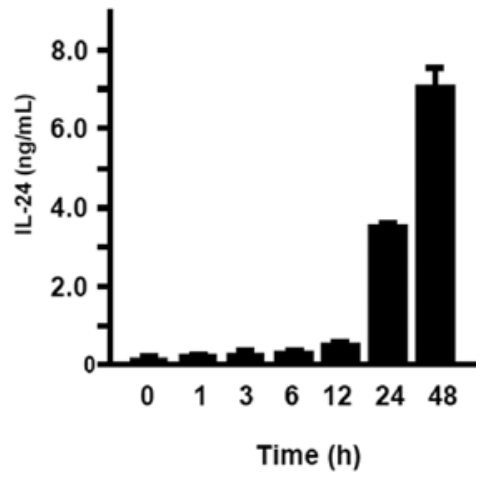

Figure 3. IL-24 mRNA expression and IL-24 secretion in human pancreatic myofibroblasts. (A and B) Dose-dependent effects of IL-1 $\beta$ on IL-24 mRNA expression and IL-24 secretion. Pancreatic myofibroblasts were incubated for $24 \mathrm{~h}$ with increasing concentrations of IL-1 1 . The levels of IL-24 mRNA expression were then determined by real-time PCR, and the IL-24 protein levels were determined by ELISA. (C and D) Kinetics of IL-24 mRNA expression and IL-24 secretion. The cells were stimulated with IL-1 $\beta(10 \mathrm{ng} / \mathrm{ml})$ for the pre-determined times, and then the IL-24 mRNA expression was determined by real-time PCR, and the IL-24 protein levels were determined by ELISA. All values are expressed as means \pm SD $(n=4)$. ${ }^{*} \mathrm{P}<0.05$, ${ }^{* *} \mathrm{P}<0.01$; a significant difference from the values for medium alone.
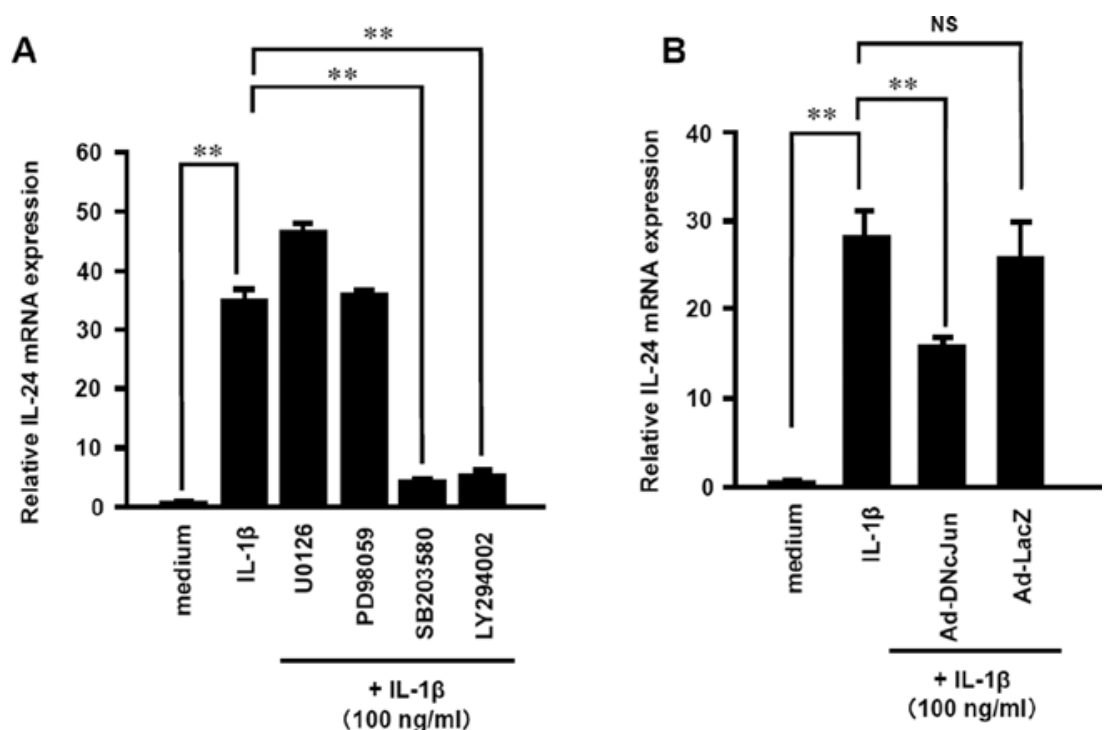

Figure 4. Effects of MAPK, PI3K and AP-1 inhibition on IL-24 mRNA expression. (A) The cells were stimulated with IL-1 13 (100 ng/ml) in the presence or absence of MEK inhibitors [U0216 $(10 \mu \mathrm{M})$ and PD98059 $(10 \mu \mathrm{M})]$, a p38 inhibitor [SB203580 $(10 \mu \mathrm{M})]$, and a PI3K inhibitor [LY294002 $(10 \mu \mathrm{M})]$ for $24 \mathrm{~h}$. The IL-24 mRNA expression levels were then determined by real-time PCR. (B) The cells were infected with an adenovirus expressing the DN-c-Jun, and at $48 \mathrm{~h}$ after infection, the cells were stimulated with IL-1 $\beta(100 \mathrm{ng} / \mathrm{ml})$ for $12 \mathrm{~h}$. The IL-24 mRNA expression was determined by real-time PCR. An adenovirus expressing LacZ was used as the negative control. The values from the real-time PCR were expressed as the IL-24 mRNA expression relative to the $\beta$-actin mRNA expression (mean $\pm \mathrm{SD}$ from 4 different experiments). ${ }^{* * *} \mathrm{P}<0.01$ vs. absence of inhibitors. NS, not significant.

Role of MAP-kinase and PI3-kinase activation in IL-24 induction. Previously, we demonstrated that IL-1 $\beta$ induces MAP-kinase activation in pancreatic myofibroblasts (23). To investigate the role of MAP-kinases in IL-1 $\beta$-induced IL-24 mRNA expression in pancreatic myofibroblasts, we evaluated the effects of p42/44 MAPK inhibitors (PD98059 and 
A

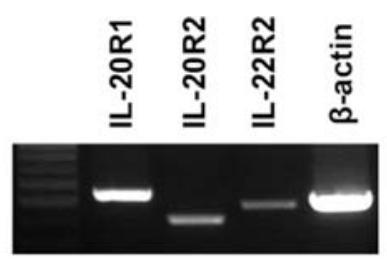

B

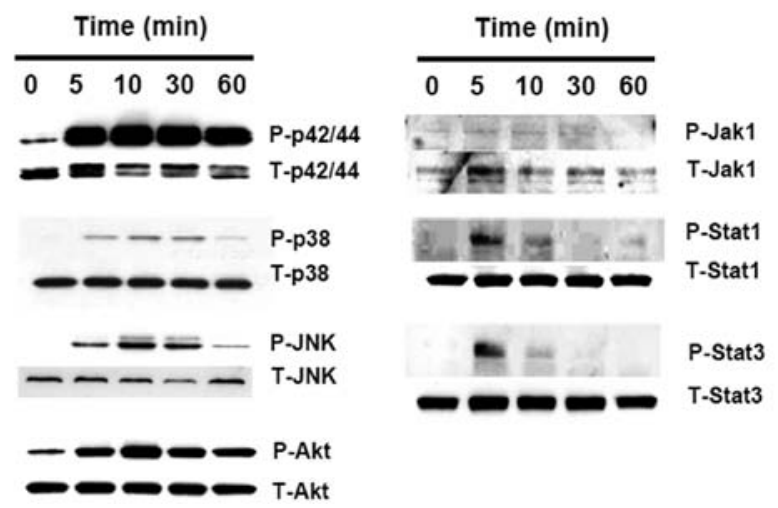

Figure 5. (A) RT-PCR analyses for the mRNA expression of IL-20R1, IL-20R2 and IL-22R1 in human pancreatic myofibroblasts. (B) IL-24 induced JAK/ STAT and MAP-kinase activation in pancreatic myofibroblasts. The cells were stimulated with IL-24 (100 ng/ml), and the activation of JAK/STAT and MAPkinases were then evaluated by Western blotting. Antibodies directed against phosphorylated (P)- and total (T)-JAK/STAT and MAP-kinases were used.

U0216) (24,25), a p38 MAPK inhibitor (SB203580) (26) and a PI3-kinase inhibitor (LY294002) (27). The p42/44 MAPK inhibitors did not have any significant effects, while the $\mathrm{p} 38$ MAPK inhibitor and PI3K inhibitor significantly reduced the IL- $\beta$-induced IL-24 mRNA expression (Fig. 4A). These observations suggest that p38 MAPK and PI3K are involved in IL-1 $\beta$-induced IL-24 mRNA expression in pancreatic myofibroblasts.

Role of AP-1 activation in IL-24 induction. Multiple recognition sites for the AP-1 transcription factor are present in the promoter region of the IL-24 gene (28). To assess the role of the transcription factor AP-1, we evaluated the effects of a recombinant adenovirus containing a dominant-negative mutant of c-Jun (Ad-DN-c-Jun) on IL-1 $\beta$-induced IL-24 mRNA expression. Pancreatic myofibroblasts were infected with this recombinant adenovirus and were cultured for $48 \mathrm{~h}$ (Fig. 4B). The cells were then stimulated for $12 \mathrm{~h}$ with IL-1 $\beta$ $(100 \mathrm{ng} / \mathrm{ml})$, and the expression of IL-24 mRNA was determined by real-time PCR. Ad-DN-c-Jun significantly inhibited the effects of IL-1 $\beta$ on IL-24 mRNA expression. These inhibitory effects were not induced by the Ad-LacZ gene, which was used as a negative control. These findings suggest that AP-1 plays a role in IL-1 $\beta$-induced IL-24 mRNA expression.

IL-24 receptor expression in pancreatic myofibroblasts. IL-24 signaling has been reported to be mediated through both IL-20R1/IL-20R2 and IL-22R1/IL-20R2 (10-12), and the expression of IL-20R1 and IL-22R1 is restricted to non-immune cells. However, their expression in pancreatic myofibroblasts remains unclear. RT-PCR studies supported the expression of IL-22R1, IL-20R1 and IL-20R2 in pancreatic myofibroblast (Fig. 5A).
IL-24 induces STAT, Akt and MAP-kinase activation in pancreatic myofibroblasts. To define the biological activities of IL-24 in pancreatic myofibroblasts, we investigated the effects of IL-24 on the activation of p42/44 (extracellular signal-regulated kinases; ERK1/2), p38, JNK, Akt, Jak1 and STAT1/3 in pancreatic myofibroblasts. IL-24 induced the phosphorylation of p42/44, p38, JNK, Jak1 and STAT1/3 as early as $5 \mathrm{~min}$ after stimulation (Fig. 5B). These observations indicated that IL-24Rs (IL-20R1/IL-20R2 and IL-22R1/IL-20R2) were functioning actively in pancreatic myofibroblasts.

\section{Discussion}

IL-24, a member of the IL-10 family of cytokines (together with IL-10, -19, -20, -22, -26, -28 and -29), shares a $20-30 \%$ amino acid homology with IL-10, IL-20 and IL-22. IL-24 interacts with two different heterodimeric receptor complexes, IL-20R1/IL-20R2 and IL-22R1/IL-20R2 (10-12). The expression of IL-20R1 and IL-22R1 is restricted to nonimmune tissues, indicating that IL-24 targets non-immune immune responses. Recent studies have revealed that when IL-24 is administered via an adenoviral vector, it selectively and efficiently kills cancer cells derived from various tissues (29-33).

The precise molecular mechanisms mediating IL-24 induction remain unclear. In the present study, we investigated IL-24 and its receptor expression in human pancreatic myofibroblasts. We report that i) human pancreatic myofibroblasts are a source of IL-24 and express the IL-24 receptor complex; ii) IL-1 $\beta$ is a potent inducer of IL-24 expression via a p38 MAPK and PI3K-dependent pathway; iii) pancreatic myofibroblasts express IL-24R complexes; and iv) IL-24 induced the activation of p42/44-/p38-MAPK, JNK1 and STAT1/3 in the pancreatic myofibroblasts.

There are few reports concerning the in vivo expression of IL-24 under normal and pathological conditions. Soo et al (34) found that IL-24 expression was greatly increased at the edges of cutaneous wounds in an animal model. A recent study by Wolk et al (16) showed that IL-24 was expressed by keratinocytes from patients with psoriasis. Recently, we reported that IL-24 expression was up-regulated in the inflamed mucosa of inflammatory bowel disease (35). However, there are no reports concerning IL-24 expression in the pancreas. In the present study, we demonstrated that IL-24 is expressed in the fibrotic tissues of chronic pancreatitis. Furthermore, IL-24expressing cells coincided with $\alpha$-SMA-immunopositive cells, suggesting that $\alpha$-SMA-immunopositive myofibroblasts are the local source of IL-24 in the pancreas.

To investigate the regulatory mechanisms involved in IL-24 expression in the pancreas, we investigated IL-24 induction in human pancreatic myofibroblasts. Among the various cytokines, IL-1 $\beta$ exerted marked effects on IL-24 induction. TNF- $\alpha$, IL-17 and LPS all weakly stimulated IL-24 expression, but these were negligible when compared to IL-1 $\beta$. Furthermore, the combination of IL- $1 \beta$ plus TNF- $\alpha$ induced strong IL-24 expression as compared to IL-1 $\beta$ alone, suggesting that IL-24 may be induced at inflamed lesions where both IL-1 $\beta$ and TNF- $\alpha$ are expressed.

In the present study, we set out to determine the relevant signaling pathways in IL-1 $\beta$-induced IL-24 mRNA expres- 
sion. Since the promoter region of the human IL-24 gene has multiple consensus binding sites for AP-1, we evaluated the effects of a recombinant adenovirus expressing a dominantnegative mutant of c-Jun (Ad-DN-c-Jun). The addition of Ad-DN-c-Jun markedly suppressed IL-1 $\beta$-induced IL-24 mRNA expression, indicating a role for AP-1 in IL-24 mRNA induction. Furthermore, a p38 MAPK inhibitor (SB203580) and a PI3K-inhibitor (LY294002) significantly inhibited IL-1 $\beta$ induced IL-24 mRNA expression. Combined with previous studies reporting that AP-1 acts downstream of evolutionarily conserved signaling pathways, such as MAPK and PI3K $(36,37)$, we concluded that p38 MAPK and PI3K pathwaydependent AP- 1 activation plays a role in IL-1 $\beta$-induced IL-24 mRNA expression.

The in vivo expression of IL-24R remains unclear. We observed that IL-20R1, IL-22R1 and IL-22R2 are expressed by pancreatic myofibroblasts (Fig. 5A). This suggests that IL-24 stimulates pancreatic myofibroblasts in an autocrine fashion. Actually, IL-24 induced a rapid activation of p42/44, $\mathrm{p} 38, \mathrm{JNK}$ and STAT1/3 molecules. It has been reported that the STAT3-mediated activation of the innate immune response contributes to a suppression of inflammatory responses (38-40), whereas the STAT3-mediated activation of the acquired immune response plays a pathogenic role by enhancing the survival of pathogenic $T$ cells $(41,42)$. These suggest that the IL-24-induced selective activation of STAT3 in pancreatic myofibroblasts may contribute to the suppression of inflammatory responses in the pancreas.

In conclusion, we demonstrated that IL-24 is expressed in pancreatic myofibroblasts. Our data suggest that IL-24 plays a role in the pathophysiology of chronic pancreatitis in an autocrine fashion. Recently, a replication-incompetent adenovirus expressing IL-24 has undergone evaluation in a phase I clinical trial for solid tumors and has proven its safety (43). Another study demonstrated that adenovirus-mediated IL-24 suppressed the proliferation of keloid fibroblasts and induced apoptosis (44). Therefore, based on the further characterization of the biological activities of IL-24, this cytokine has potential for clinical applications to regulate the pathophysiology of chronic pancreatitis.

\section{References}

1. Shimizu K: Mechanisms of pancreatic fibrosis and applications to the treatment of chronic pancreatitis. J Gastroenterol 43: 823-832, 2008.

2. Suda K, Fukumura Y, Takase M, et al: Activated perilobular, not periacinar, pancreatic stellate cells contribute to fibrogenesis in chronic alcoholic pancreatitis. Pathol Int 57: 21-25, 2007.

3. Suda K, Shiotsu H, Nakamura T and Akai J: Pancreatic fibrosis in patients with chronic alcohol abuse: correlation with alcoholic pancreatitis. Am J Gastroenterol 89: 2060-2062, 1994.

4. Saotome T, Inoue H, Fujimiya M, Fujiyama Y and Bamba T: Morphological and immunocytochemical identification of periacinar fibroblast-like cells derived from human pancreatic acini. Pancreas 14: 373-382, 1997.

5. Nishida A, Andoh A, Inatomi O and Fujiyama Y: Interleukin-32 expression in the pancreas. J Biol Chem 284: 17868-17876, 2009.

6. Masamune A and Shimosegawa T: Signal transduction in pancreatic stellate cells. J Gastroenterol 44: 249-260, 2009.

7. Jiang H, Lin JJ, Su ZZ, Goldstein NI and Fisher PB: Subtraction hybridization identifies a novel melanoma differentiation associated gene, mda-7, modulated during human melanoma differentiation, growth and progression. Oncogene 11: 2477-2486, 1995.
8. Caudell EG, Mumm JB, Poindexter N, et al: The protein product of the tumor suppressor gene, melanoma differentiation-associated gene 7 , exhibits immunostimulatory activity and is designated IL-24. J Immunol 168: 6041-6046, 2002.

9. Huang EY, Madireddi MT, Gopalkrishnan RV, et al: Genomic structure, chromosomal localization and expression profile of a novel melanoma differentiation associated (mda-7) gene with cancer specific growth suppressing and apoptosis inducing properties. Oncogene 20: 7051-7063, 2001.

10. Wang M, Tan Z, Zhang R, Kotenko SV and Liang P: Interleukin 24 (MDA-7/MOB-5) signals through two heterodimeric receptors, IL-22R1/IL-20R2 and IL-20R1/IL-20R2. J Biol Chem 277: 7341-7347, 2002.

11. Wang M and Liang P: Interleukin-24 and its receptors. Immunology 114: 166-170, 2005 .

12. Dumoutier L,Leemans C,Lejeune D, Kotenko SV and Renauld JC: Cutting edge: STAT activation by IL-19, IL-20 and mda-7 through IL-20 receptor complexes of two types. J Immunol 167: 3545-3549, 2001.

13. Dumoutier L and Renauld JC: Viral and cellular interleukin-10 (IL-10)-related cytokines: from structures to functions. Eur Cytokine Netw 13: 5-15, 2002.

14. Nagalakshmi ML, Murphy E, McClanahan T and de WaalMalefyt R: Expression patterns of IL-10 ligand and receptor gene families provide leads for biological characterization. Int Immunopharmacol 4: 577-592, 2004.

15. Kunz S, Wolk K, Witte E, et al: Interleukin (IL)-19, IL-20 and IL-24 are produced by and act on keratinocytes and are distinct from classical ILs. Exp Dermatol 15: 991-1004, 2006.

16. Wolk K, Kunz S, Asadullah K and Sabat R: Cutting edge: immune cells as sources and targets of the IL-10 family members? J Immunol 168: 5397-5402, 2002.

17. Fujino S, Andoh A, Bamba S, et al: Increased expression of interleukin 17 in inflammatory bowel disease. Gut 52: 65-70, 2003.

18. Andoh A, Shioya M, Nishida A, et al: Expression of IL-24, an activator of the JAK1/STAT3/SOCS3 cascade, is enhanced in inflammatory bowel disease. J Immunol 183: 687-695, 2009.

19. Xie MH, Aggarwal S, Ho WH, et al: Interleukin (IL)-22, a novel human cytokine that signals through the interferon receptor-related proteins CRF2-4 and IL-22R. J Biol Chem 275: 31335-31339, 2000.

20. Andoh A, Takaya H, Saotome T, et al: Cytokine regulation of chemokine (IL-8, MCP-1 and RANTES) gene expression in human pancreatic periacinar myofibroblasts. Gastroenterology 119: 211-219, 2000.

21. Yasumoto H, Kim S, Zhan Y, et al: Dominant negative c-jun gene transfer inhibits vascular smooth muscle cell proliferation and neointimal hyperplasia in rats. Gene Ther 8: 1682-1689, 2001.

22. Bamba S, Andoh A, Yasui H, Makino J, Kim S and Fujiyama Y: Regulation of IL-11 expression in intestinal myofibroblasts: role of c-Jun AP-1- and MAPK-dependent pathways. Am J Physiol Gastrointest Liver Physiol 285: G529-G538, 2003.

23. Shimada M, Andoh A, Hata K, et al: IL-6 secretion by human pancreatic periacinar myofibroblasts in response to inflammatory mediators. J Immunol 168: 861-868, 2002.

24. Alessi DR, Cuenda A, Cohen P, Dudley DT and Saltiel AR: PD 098059 is a specific inhibitor of the activation of mitogenactivated protein kinase kinase in vitro and in vivo. $\mathrm{J}$ Biol Chem 270: 27489-27494, 1995.

25. Favata MF, Horiuchi KY, Manos EJ, et al: Identification of a novel inhibitor of mitogen-activated protein kinase kinase. J Biol Chem 273: 18623-18632, 1998.

26. Cuenda A, Rouse J, Doza YN, et al: SB 203580 is a specific inhibitor of a MAP kinase homologue which is stimulated by cellular stresses and interleukin-1. FEBS Lett 364: 229-233, 1995.

27. Fang J, Ding M, Yang L, Liu LZ and Jiang BH: PI3K/PTEN/AKT signaling regulates prostate tumor angiogenesis. Cell Signal 19: 2487-2497, 2007.

28. Madireddi MT, Dent P and Fisher PB: AP-1 and C/EBP transcription factors contribute to mda-7 gene promoter activity during human melanoma differentiation. J Cell Physiol 185: 36-46, 2000.

29. Su Z, Emdad L, Sauane M, et al: Unique aspects of mda-7/IL-24 antitumor bystander activity: establishing a role for secretion of MDA-7/IL-24 protein by normal cells. Oncogene 24: 7552-7566, 2005.

30. Kreis S, Philippidou D, Margue C, et al: Recombinant interleukin-24 lacks apoptosis-inducing properties in melanoma cells. PLoS One 2: e1300, 2007.

31. Gupta P, Su ZZ, Lebedeva IV, et al: mda-7/IL-24: multifunctional cancer-specific apoptosis-inducing cytokine. Pharmacol Ther 111: 596-628, 2006. 
32. Chada S, Sutton RB, Ekmekcioglu S, et al: MDA-7/IL-24 is a unique cytokine-tumor suppressor in the IL-10 family. Int Immunopharmacol 4: 649-667, 2004.

33. Sauane M, Gopalkrishnan RV, Sarkar D, et al: MDA-7/IL-24: novel cancer growth-suppressing and apoptosis-inducing cytokine. Cytokine Growth Factor Rev 14: 35-51, 2003.

34. Soo C, Shaw WW, Freymiller E, et al: Cutaneous rat wounds express c49a, a novel gene with homology to the human melanoma differentiation associated gene, mda-7. J Cell Biochem 74: 1-10, 1999.

35. Shioya M, Nishida A, Yagi Y, et al: Epithelial overexpression of interleukin-32alpha in inflammatory bowel disease. Clin Exp Immunol 149: 480-486, 2007.

36. Ding SZ, Olekhnovich IN, Cover TL, Peek RM Jr, Smith MF Jr and Goldberg JB: Helicobacter pylori and mitogen-activated protein kinases mediate activator protein-1 (AP-1) subcomponent protein expression and DNA-binding activity in gastric epithelial cells. FEMS Immunol Med Microbiol 53: 385-394, 2008.

37. Mukhopadhyay S, Mukherjee S, Smith M and Das SK: Activation of MAPK/AP-1 signaling pathway in lung injury induced by 2 -chloroethyl ethyl sulfide, a mustard gas analog. Toxicol Lett 181: $112-117,2008$.

38. Welte T, Zhang SS, Wang T, et al: STAT3 deletion during hematopoiesis causes Crohn's disease-like pathogenesis and lethality: a critical role of STAT3 in innate immunity. Proc Natl Acad Sci USA 100: 1879-1884, 2003.
39. Tebbutt NC, Giraud AS, Inglese M, et al: Reciprocal regulation of gastrointestinal homeostasis by SHP2 and STAT-mediated trefoil gene activation in gp130 mutant mice. Nat Med 8: 1089-1097, 2002.

40. Sugimoto K: Role of STAT3 in inflammatory bowel disease. World J Gastroenterol 14: 5110-5114, 2008.

41. Mizoguchi A and Mizoguchi E: Inflammatory bowel disease, past, present and future: lessons from animal models. J Gastroenterol 43: 1-17, 2008.

42. Hokama A, Mizoguchi E, Sugimoto K, et al: Induced reactivity of intestinal CD4(+) T cells with an epithelial cell lectin, galectin-4, contributes to exacerbation of intestinal inflammation. Immunity 20: 681-693, 2004

43. Eager R, Harle L and Nemunaitis J: Ad-MDA-7; INGN 241: a review of preclinical and clinical experience. Expert Opin Biol Ther 8: 1633-1643, 2008.

44. Liang J, Huang RL, Huang Q, Peng Z, Zhang PH and Wu ZX: Adenovirus-mediated human interleukin-24 (MDA-7/IL-24) selectively suppresses proliferation and induces apoptosis in keloid fibroblasts. Ann Plast Surg 66: 660-666, 2011. 